\title{
Genetic heterogeneity of pediatric systemic lupus erythematosus with lymphoproliferation
}

Guo-min Li

Children's Hospital of Fudan University

Yi-fan Li

children's hospital of fudan university

Hai-mei Liu

Children's Hospital of Fudan University

Yu Shi

Children's Hospital of Fudan University

Wan-zhen Guan

Children's Hospital of Fudan University

Tao Zhang

Children's Hospital of Fudan University

Yao Wen

Children's Hospital of Fudan University

Bing-bing Wu

Children's Hospital of Fudan University

Hong Xu

Children's Hospital of Fudan University

Li Sun ( $\square$ lillysun@263.net)

\section{Research article}

Keywords: lymphoproliferation, NRAS gene mutation, somatic mutation, systemic lupus erythematosus

Posted Date: December 19th, 2019

DOI: https://doi.org/10.21203/rs.2.19268/v1

License: () (1) This work is licensed under a Creative Commons Attribution 4.0 International License. Read Full License

Version of Record: A version of this preprint was published at Medicine on May 15th, 2020. See the published version at https://doi.org/10.1097/MD.0000000000020232. 


\section{Abstract}

Purpose: Systemic lupus erythematosus (SLE) is a rare autoimmune disease, which is more severe in case of pediatric onset. This may be due to greater involvement of genetic factors compared with adult forms. In recent years, multiple monogenic diseases with early-onset autoimmunity and lymphoproliferation have been identified, such as Autoimmune lymphoproliferative syndrome (ALPS), RAS-associated autoimmune leukoproliferative disease (RALD), Signal transducer and activator of transcription 3 (STAT3) Gain-of-Function (GOF) syndrome and Interleukin-2 receptor a (IL2RA) deficiency. Therefore, we performed whole exome sequencing in SLE children with lymphoproliferation to identify genes associated with these conditions.

Methods: We enrolled seven SLE patients with lymphoproliferation, which are from different families. Demographic data, clinical manifestations, laboratory and histopathological findings, treatment, and outcome were documented. WES was performed in seven cases and their families. Suspected variants were confirmed by Sanger sequencing. Protein levels were detected in patients with gene mutations by Western blot.

Results: Four patients were male, and three were female. No consanguinity was reported within the seven families. The average age at onset was 5.0 years (range from 1.2 to 10.0 years). The most common features were renal (7/7 patients), hematological (6/7 patients) involvement, and recurrent fever (6/7patients) while only two patients presented with skin involvement. Antinuclear antibodies ( ANA) at a titer of $\geq 1: 320$ was positive in all patients. All patients fulfilled four 2019 European League Against Rheumatism/American College of Rheumatology (EULAR/ACR) criteria for the classification of SLE. We identified a somatic activating NRAS variant (c.38 A>G, p.G13C) in peripheral venous blood from four patients, at levels ranging from $8.8 \%$ to $42.8 \%$ in variant tissues, that was absent from their parents. BCL-2-Interacting Mediator of Cell Death (BIM) levels in peripheral blood mononuclear cells (PBMCs) from four patients were markedly reduced, whereas those in control was normal. Another two mutations, c.559C>T (p.Q187X) in the TNFAIP3 gene and c.3061G>A (p.E1021K) in PIK3CD gene, were detected in two patients, respectively.

Conclusion: SLE is a novel phenotype of germline mutation in PI3CKD gene and somatic mutation in NRAS gene. These genes, NRAS , TNFAIP3 and PIK3CD , should be considered as candidates for SLE children with lymphoproliferation. If patients with SLE and lymphoproliferation presented with renal and hematological involvement, and recurrent fever, they need gene testing, especially in male patient.

\section{Background}

Autoimmune and immunodeficiency diseases are outcomes of a dysfunctional immune system and represent two sides of the same coin [1]. Multiple singlegene defects have been identified, resulting in rare diseases with features of both autoimmunity and immunodeficiency [2-5]. Systemic lupus erythematosus (SLE; OMIM 152700) is a prototype autoimmune disease with a strong genetic component, characterized by differences in autoantibody profile, serum cytokines, and a multisystem involvement commonly affecting the skin, renal, musculoskeletal, and hematopoietic systems ${ }^{[6]}$. Early-onset, familial, and/or syndromic SLE may reveal monogenic pathologies ${ }^{[7]}$. Autoimmune lymphoproliferative syndrome (ALPS; OMIM 601859), a disease of lymphocyte homeostasis caused by dysfunction of the FAS-mediated apoptotic pathway, caused by defective lymphocyte homeostasis, is characterized by lymphadenopathy, hepatomegaly, splenomegaly and autoimmune disease ${ }^{[2]}$. RAS-associated autoimmune leukoproliferative disease (RALD; OMIM 614470) also presents as autoimmunity, lymphadenopathy, and/or splenomegaly ${ }^{[8]}$. On the molecular level, RALD is defined by somatic mutations of either NRAS or KRAS gene in a subset of hematopoietic cells ${ }^{[3,9]}$. Signal transducer and activator of transcription 3 (STAT3) gain-of-function (GOF) syndrome (OMIM 615952) is a new clinical entity characterized by early-onset poly-autoimmunity, lymphoproliferation, and growth failure ${ }^{[4]}$. Cell-surface interleukin-2 receptor a (IL-2RA, CD25) expression is critical for maintaining immune function and homeostasis. Human IL2RA null mutation mediates immunodeficiency with lymphoproliferation and autoimmunity (IL2RA deficiency; OMIM 606367) ${ }^{[5]}$. Therefore, we performed whole exome sequencing in SLE children with lymphoproliferation to identify genes associated with these conditions.

\section{Method}

The study was approved by the Ethics Committee at the Children's Hospital of Fudan University, Shanghai, China. All the patients' parents provided written informed consent for enrollment in this study.

Patients

In total, seven Chinese SLE children from seven unrelated families were enrolled in this study. All patients fulfilled four 2019 European League Against Rheumatism/American College of Rheumatology (EULAR/ACR) criteria for the classification of SLE ${ }^{[10]}$. Demographic data, clinical manifestations, laboratory and histopathological findings, treatment, and outcome were documented. All patients were admitted to or followed up at our center (Children's Hospital of Fudan University) between 2011 and 2019. The deadline date of follow-up was August 2019.

\section{DNA Sequencing}

Genomic DNA was extracted and purified from peripheral leukocytes in whole-blood samples by a DNA isolation kit (Qiagen, Hilden, Germany). WES analysis and bioinformatic analysis was performed in patient's families as previously described ${ }^{[11]}$. Only genes listed in OMIM (Online Mendelian Inheritance in Man: https://www.omim.org/) were considered candidate causative genes. Variants identified by WES analysis were confirmed by Sanger sequencing.

PBMC Isolation and Cell Culture

Peripheral venous blood was drawn from one healthy volunteer and four patients with NRAS mutation. The ethylenediaminetetraacetic acid (EDTA) anticoagulated blood was diluted with an equal volume of phosphate-buffered saline, $\mathrm{pH}$ 7.4 (PBS). The diluted blood was carefully added to the top of the

Page 2/11 
Ficoll-Paque PLUS (GE Healthcare) and centrifuged at $2000 \mathrm{rpm}$ for $10 \mathrm{~min}$ at room temperature. The top layer containing plasma was removed, and the remaining blood was diluted with an equal volume of PBS. After being washed twice in PBS, the peripheral blood mononuclear cells (PBMCs) were cultured in RPMI 1640 supplemented with $10 \%$ FCS at a density of $1 \times 10^{6}$ cells $/ \mathrm{mL}$. After incubation in a 24 -well plate at $37^{\circ} \mathrm{C}$ in $5 \% \mathrm{CO}_{2}$ for $24 \mathrm{~h}$, the cells were harvested for subsequent experiments.

Western Blot

Total and nuclear proteins was extracted using a Protein Extraction Kit (Beyotime, Shanghai, China) following the manufacturer's instructions. Equal amounts of cytoplasmic or nuclear extracts were separated by $10 \%$ sodium dodecyl sulfate polyacrylamide gel electrophoresis (SDS-PAGE) and transferred to $0.45 \mu$ m PVDF membranes (Millipore, MA, USA). Blots were probed with primary antibodies against BCL-2-Interacting Mediator of Cell Death (BIM) and $\beta$-actin (Cell Signaling Technology, Beverly, MA). Primary antibodies were detected with horseradish peroxidase-conjugated secondary antibody. Visualization was conducted using an ECL peroxidase substrate.

\section{Results}

Clinical data

Clinical characteristics

Seven patients were Chinese. Four children were male, and three were female. No consanguinity was reported within the seven families. The average age at onset was 5.0 years (range from 1.2 to 10.0 years). The most common features were renal (proteinuria and/or hematuria; $7 / 7$ patients) and hematological (cytopenia; 6/7 patients) involvement, and recurrent fever (6/7patients) while only two patients presented with skin involvement. Antinuclear antibodies (ANA) at a titer of $\geq 1: 320$ was positive in all patients. They fulfilled 2019 EULAR/ACR criteria for the classification of SLE ${ }^{[10]}$. All patients had hepatomegaly and/or splenomegaly, and/or lymphadenectasis. Bone marrow aspiration in all patients showed no malignant cells and nonspecific changes. Cervical lymph node biopsy also revealed no malignant cells and nonspecific changes (lymphocyte proliferation) in patient 2 and 5 . Liver biopsy revealed fibrosis in patient 7. Patient 1 has been accompanied by macrophage activation syndrome (MAS) before admitting to our center, and P3 presented with MAS after disease flare, both characterized by cytopenia, hyperferritinemia, hypertriglyceridemia, hypofibrinogenemia, and increased levels of Alanine Aminotransferase (ALT), Glutamic-oxalacetic Transaminase (GOT) and lactate dehydrogenase (LDH). The clinical and laboratory characteristics of the patients are summarized in Table 1 and Table 2.

Table 1

Clinical Features of seven SLE patients with lymphoproliferation

\begin{tabular}{|c|c|c|c|c|c|c|c|c|c|}
\hline \multirow[t]{2}{*}{ Case } & \multirow[t]{2}{*}{ G } & \multirow{2}{*}{$\begin{array}{l}\text { Age } \\
\text { at } \\
\text { onset(y) }\end{array}$} & \multirow[t]{2}{*}{ initial symptoms } & \multicolumn{3}{|c|}{ Affected system or symptom } & \multicolumn{3}{|c|}{ Lymphoproliferation } \\
\hline & & & & hematological & Renal & Others & Hepatomegaly & Splenomegaly & Lymphadenectasis \\
\hline 1 & M & 1.5 & Epistaxis & $\begin{array}{l}\text { Thrombocytopenia } \\
\text { Hypoleucocytosis } \\
\text { Anemia }\end{array}$ & $\begin{array}{l}\text { Proteinuria } \\
\text { Hematuria }\end{array}$ & $\begin{array}{l}\text { Recurrent } \\
\text { fever }\end{array}$ & $\mathrm{Y}$ & $\mathrm{N}$ & $\mathrm{N}$ \\
\hline 2 & M & 4.0 & $\begin{array}{l}\text { Cervical } \\
\text { lymphadenopathy }\end{array}$ & $\begin{array}{l}\text { Thrombocytopenia } \\
\text { Anemia }\end{array}$ & Proteinuria & $\begin{array}{l}\text { Recurrent } \\
\text { fever }\end{array}$ & $\mathrm{N}$ & $\mathrm{N}$ & Neck \\
\hline 3 & M & 3.0 & $\begin{array}{l}\text { Armpit } \\
\text { Lymphadenectasis } \\
\text { Skin rash }\end{array}$ & $\begin{array}{l}\text { Thrombocytopenia } \\
\text { Anemia }\end{array}$ & Proteinuria & $\begin{array}{l}\text { Recurrent } \\
\text { fever }\end{array}$ & $\mathrm{Y}$ & $\mathrm{Y}$ & $\begin{array}{l}\text { Neck, armpit, } \\
\text { groin }\end{array}$ \\
\hline 4 & $\mathrm{~F}$ & 1.2 & Hepatosplenomegaly & $\begin{array}{l}\text { Thrombocytopenia } \\
\text { Anemia }\end{array}$ & Proteinuria & $\begin{array}{l}\text { Recurrent } \\
\text { fever }\end{array}$ & $\mathrm{Y}$ & $\mathrm{Y}$ & $\mathrm{N}$ \\
\hline 5 & $\mathrm{~F}$ & 8.5 & $\begin{array}{l}\text { Purpura } \\
\text { in lower limbs }\end{array}$ & $\mathrm{N}$ & $\begin{array}{l}\text { Proteinuria } \\
\text { Hematuria }\end{array}$ & $\mathrm{N}$ & $\mathrm{N}$ & $\mathrm{N}$ & Neck \\
\hline 6 & M & 10.0 & Splenomegaly & Hypoleucocytosis & $\begin{array}{l}\text { Proteinuria } \\
\text { Hematuria }\end{array}$ & $\begin{array}{l}\text { Recurrent } \\
\text { fever }\end{array}$ & $\mathrm{N}$ & $\mathrm{Y}$ & Neck \\
\hline 7 & $\mathrm{~F}$ & 7.0 & Hepatosplenomegaly & $\begin{array}{l}\text { Thrombocytopenia } \\
\text { Anemia }\end{array}$ & $\begin{array}{l}\text { Proteinuria } \\
\text { Hematuria }\end{array}$ & $\begin{array}{l}\text { Fever } \\
\text { Rash }\end{array}$ & $\mathrm{Y}$ & $\mathrm{Y}$ & $\mathrm{N}$ \\
\hline
\end{tabular}


Table 2

laboratory finding of seven patients

\begin{tabular}{|c|c|c|c|c|c|c|c|c|c|c|c|}
\hline \multirow[t]{2}{*}{ Case } & \multicolumn{3}{|c|}{ Autoantibody } & \multicolumn{3}{|c|}{ Level of complement } & \multicolumn{3}{|c|}{ Anti-phospholipid antibody } & \multirow{2}{*}{$\begin{array}{l}\text { Direct } \\
\text { Coombs } \\
\text { test }\end{array}$} & \multirow[t]{2}{*}{ Gene } \\
\hline & ANA & $\begin{array}{l}\text { Anti- } \\
\text { dsDNA }\end{array}$ & Others (positive) & $\mathrm{C} 3(\mathrm{~g} / \mathrm{L})$ & $\mathrm{C} 4(\mathrm{~g} / \mathrm{L})$ & $\mathrm{CH} 50(\mathrm{U} / \mathrm{L})$ & $\begin{array}{l}\text { lupus } \\
\text { anticoagulant }\end{array}$ & $\begin{array}{l}\text { anticardiolipin } \\
\text { antibody }\end{array}$ & $\begin{array}{l}\text { anti- } \beta 2 \\
\text { glycoprotein } \\
\text { I }\end{array}$ & & \\
\hline 1 & $\mathrm{P}$ & $\mathrm{N}$ & - & 0.72 & 0.11 & 30 & $\mathrm{~N}$ & $\mathrm{P}$ & $\mathrm{P}$ & $\mathrm{P}$ & NRAS \\
\hline 2 & $P$ & $\mathrm{P}$ & $\begin{array}{l}\text { SSA } \square \text { p-ANCA } \\
\text { MPO }\end{array}$ & 0.29 & 0.04 & 10 & $\mathrm{~N}$ & $\mathrm{~N}$ & $\mathrm{~N}$ & $\mathrm{P}$ & NRAS \\
\hline 3 & $\mathrm{P}$ & $\mathrm{P}$ & U1-RNP, Anti-Sm & 0.51 & 0.0 & 22 & $\mathrm{~N}$ & $\mathrm{P}$ & $\mathrm{N}$ & $\mathrm{P}$ & NRAS \\
\hline 4 & $\mathrm{P}$ & $\mathrm{P}$ & $\begin{array}{l}\text { U1-RNP, Anti-Sm } \\
\text { p-ANCA }\end{array}$ & 0.77 & 0.01 & 22 & $\mathrm{~N}$ & $\mathrm{~N}$ & $\mathrm{~N}$ & $\mathrm{~N}$ & NRAS \\
\hline 5 & $\mathrm{P}$ & $\mathrm{P}$ & $\begin{array}{l}\text { Anti-nucleosome } \\
\text { Anti- } \\
\text { ribonucleoprotein }\end{array}$ & 0.44 & 0.02 & 5 & $\mathrm{~N}$ & $\mathrm{~N}$ & $N$ & $\mathrm{~N}$ & No \\
\hline 6 & $\mathrm{P}$ & $\mathrm{N}$ & p-ANCA & 0.11 & 0.05 & 3 & $\mathrm{~N}$ & $\mathrm{~N}$ & $\mathrm{~N}$ & $\mathrm{~N}$ & PIK3CD \\
\hline 7 & $\mathrm{P}$ & $\mathrm{N}$ & $\begin{array}{l}\text { SSA }] p-A N C A \\
\text { MPO }\end{array}$ & 0.22 & 0.06 & 10 & $\mathrm{~N}$ & $\mathrm{~N}$ & $\mathrm{~N}$ & $\mathrm{P}$ & TNFAIP3 \\
\hline
\end{tabular}

Immunological Features

The immunological characteristics of the patient are listed in Table 3. The B lymphocyte subgroups were elevated in patient 1, 3-5, normal in patient 4, and decreased in patient 6,7. However, the immunoglobulin $(\mathrm{lg}) \mathrm{G}$ level was elevated in all patients. Increased IgA level in patient 1-3,6 and normal IgA level in patient 4,5,7 was detected. IgM level was elevated in patient 1,6,7, and normal in patient 2-5. Except normal IgE level in patient 3, increased IgE level was detected in others. We observed that the proportion of double-negative T cells (DNT) $\left(\mathrm{CD} 3^{+} \mathrm{CD} 4^{-} \mathrm{CD} 8^{-}\right)$was increased in patient 7 , while it was normal in others. The proportion of $\mathrm{CD} 3^{+} \mathrm{CD} 4^{+} \mathrm{CD} 8^{-} \mathrm{T}$ cells was reduced in petient1,4-6 and normal in patient $2,3,7$. The proportion of $\mathrm{CD} 3^{+} \mathrm{CD} 4^{-} \mathrm{CD} 8^{+} \mathrm{T}$ cells was elevated in petient3,6,7 and normal in patient $1,2,4,5$. Reduced numbers of nature kill cells $\left(\mathrm{CD} 3^{-} \mathrm{CD} 16^{+} \mathrm{CD} 56^{+}\right)$in patient $2-6$ and normal numbers of nature kill cells $\left(\mathrm{CD}^{-} \mathrm{CD} 16^{+} \mathrm{CD} 56^{+}\right)$in patient 1,7 were detected. Obvious monocytosis were found in almost all patients by routine blood examination. 
Table 3

Routine Evaluation of Immunological Function in seven SLE patients with lymphoproliferation

\begin{tabular}{|c|c|c|c|c|c|c|c|c|}
\hline $\begin{array}{l}\text { Lymphocyte } \\
\text { subgroup }\end{array}$ & Case 1 & Case 2 & Case 3 & Case 4 & Case 5 & Case 6 & Case 7 & $\begin{array}{l}\text { Normal } \\
\text { range }\end{array}$ \\
\hline $\mathrm{CD}^{+} / \mathrm{CD}^{+}$ & 0.98 & 1.04 & 0.85 & 0.45 & 0.85 & 0.3 & 0.84 & \\
\hline $\mathrm{CD} 16^{+} \mathrm{CD} 56^{+}$ & 108.1 & 332.1 & 127.0 & 1110.4 & 53.9 & 355.4 & 114.9 & \\
\hline $\mathrm{CD} 16^{+} \mathrm{CD} 6^{+}(\%)$ & 14.71 & 11.4 & 3.0 & 21.9 & 2.2 & 10.0 & 16.3 & $11-23$ \\
\hline $\mathrm{CD}_{19}{ }^{+}$ & 284.4 & 429.1 & 632.0 & 1428.9 & 871.6 & 41.4 & 71.3 & \\
\hline $\mathrm{CD} 19^{+}(\%)$ & 38.7 & 14.4 & 15.0 & 28.2 & 34.9 & 1.2 & 10.1 & $14-21$ \\
\hline $\mathrm{CD}^{+}$ & 339.3 & 2087.3 & 3385.0 & 2330.6 & 1555.5 & 3096.8 & 502.7 & \\
\hline $\mathrm{CD}^{+}(\%)$ & 46.2 & 71.7 & 81.0 & 45.9 & 62.3 & 86.8 & 71.4 & $64-73$ \\
\hline $\mathrm{CD}^{+}$ & 163.0 & 1011.3 & 1490.0 & 670.3 & 666.8 & 705.5 & 224.7 & \\
\hline $\mathrm{CD}^{+}(\%)$ & 22.2 & 34.7 & 35.0 & 13.2 & 26.7 & 19.8 & 31.9 & $29-36$ \\
\hline $\mathrm{CD}^{+}$ & 166.3 & 973.1 & 1744.0 & 1498.1 & 788.2 & 2356.3 & 267.2 & \\
\hline $\mathrm{CD}^{+}(\%)$ & 22.6 & 33.4 & 42.0 & 29.5 & 31.6 & 66.0 & 38.0 & $24-34$ \\
\hline DNT(\%) & 1.4 & 3.6 & 4.0 & 3.2 & 4.3 & 1.0 & 4.2 & $0.37-4.16$ \\
\hline Monocyte (\%) & 16.7 & 11.6 & 12.6 & 9.8 & 2.4 & 8.8 & 21.6 & $3-8$ \\
\hline \multicolumn{9}{|l|}{ Immunoglobulin } \\
\hline $\lg G(g / L)$ & 21.4 & 25.7 & 26.4 & 32.8 & 15.8 & 37.9 & 21.6 & $5.0-12.7$ \\
\hline $\lg A(g / L)$ & 1.5 & 2.8 & 2.8 & 1.0 & 1.8 & 2.3 & 1.5 & $0.3-1.9$ \\
\hline $\lg M(g / L)$ & 3.6 & 2.4 & 1.2 & 2.5 & 1.2 & 3.1 & 9.3 & $0.7-2.0$ \\
\hline $\lg \mathrm{E}(\mathrm{KU} / \mathrm{L})$ & 265.1 & 147.38 & 14.5 & 288.0 & 802.7 & 972.4 & 207.8 & $<100$ \\
\hline
\end{tabular}

Therapy and following up

The mean follow-up time was 4.5 years (range from 1.6-7.7 year). All patients were treated with hydroxychloroquine (HCQ), glucocorticoid (GC), and immunosuppressive agents, including cyclosporine, mycophenolate mofetil (MMF), tacrolimus, and cyclophosphamide (CTX) (see Fig. 1). Methylprednisolone pulse therapy was given to patient 1 (at local hospital), 4, 5 at the beginning, because of severe conditions. MMF was switched to sirolimus in patient 6 , and Etanercept was added to patient 7 after molecular diagnosis. Patient 1 was treated with cyclosporine at the beginning, and patient 3 was replaced with cyclosporine, both because of being complicated by MAS. The disease was flare again during tapering glucocorticoid and reducing the dose of immunosuppressive agents in patient 1,3,4,7.

Whole exome sequencing

An average of $11.6 \mathrm{~Gb}$ of raw sequence data was generated with $92.68 \times$ depth of exome target regions for each individual as paired-end 150 base pair reads. $91.4 \%$ of the raw date sequencing quality was above Q30. The coverage of at least $10 \times$ and $20 \times$ of the target regions was $99.62 \%$ and $97.6 \%$ respectively. We identified a heterozygous c.38 A>G mutation (p.G13C) in NRAS gene in peripheral venous blood from patient1-4. Neither parents harbored a mutation in the NRAS gene, suggesting that the patient harbored a de novo germline or somatic mutation (Fig. 2). Another two heterozygous mutations, c.559C > T (p.Q187X) in the TNFAIP3 gene and c.3061G > A (p.E1021K) in PIK3CD gene, were detected in two patients, respectively. The former is from her father, the latter is absent from their parents. No mutations were detected in P5, and no mutations in other genes associated with primary immunodeficiencies and monogenic SLE were identified in all patients.

Sanger sequencing

All mutations were confirmed by Sanger sequencing in seven families, respectively (Fig. 3). Using DNA extracted from somatic cells (nails and buccal mucosa) in patients with NRAS mutation, NRAS exon 1 was amplified by PCR, and then the products were cloned. Mutated alleles were observed less frequently in the buccal mucosa and nails (42.8 and $8.8 \%$, respectively) than in the blood (52.0\%) in patient 1 (Fig. $3 \mathrm{a}$ ). Similar results were found in other three patients (Fig. 3b). The exon, including 559C > T in the TNFAIP3 gene, were screened by Sanger sequencing in patient7's grandparents. The mutation was not identified in her grandparents. All mutations were checked in mutation databases on human populations, such as ExAC Browser (http://exac.broadinstitute.org/), 1000Genomes (http://www.internationalgenome.org/), and HGMD (http://www.hgmd.cf.ac.uk/ac/index.php). They were all found in the above mutation databases. 
Levels of BIM in PBMCs from Patients

Gain-of-function NRAS mutations hyperactivate the RAS/RAF/ERK pathway, which in turn negatively regulates BIM expression in patients with NRAS mutation. Western blot analysis showed that BIM levels in PBMCs from four patients were markedly reduced, whereas those in control was normal (Fig. 4).

\section{Discussion}

Here, we report a cohort of patients with SLE and chronic lymphoproliferation. The clinical and laboratory data in all patients fulfilled four 2019EULAR/ACR criteria for the classification of SLE ${ }^{[10]}$. The average age at onset was 5.0 years (range from 1.2 to 10.0 years). The male to female ratio is $4: 3$. In recent years, multiple monogenic causes of early-onset autoimmunity and lymphoproliferation have been identified, such as FAS, CASPAS10, NRAS, IL2RA, and STAT3 gene [5,12-17]. Therefore, we performed WES in our patients. Results in our study showed germline mutation in TNFAIP3, PIK3CD gene and somatic mutation in NRAS gene, and no mutations in other genes associated with primary immunodeficiencies and monogenic SLE in patients, such as FAS, CASPAS10, IL2RA, STAT3 gene.

WES revealed a heterozygous c.559C >T (p.Q187X) mutation in the TNFAIP3 gene in patient 7, which is from her father, and not identified in her grandparents. The patient was reported in previously our study ${ }^{[18]}$. Recently, heterozygous germline mutations in the TNFAIP3 gene have been found to cause the

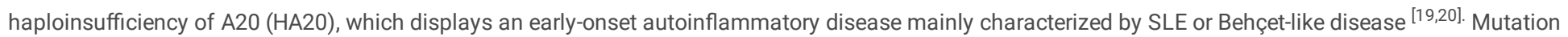
in TNFAIP3 gene also has been reported in children with uncharacterized autoimmune diseases and lymphoproliferation, and ALPS phenotype [21,22].

The de novo mutation, c.3061G>A (p.E1021K) in PIK3CD gene, was detected in patient 6, also reported in previously our study [23]. Gain of function (GOF) mutations in PIK3CD gene, encoding PI3K p1108, were recently associated with a novel combined immune deficiency characterized by recurrent sinopulmonary infections, reduced class-switched memory B cells, lymphadenopathy, CD4+ lymphopenia, CMV and/or EBV viremia and EBV-related lymphoma ${ }^{[24,25]}$. PI3Kס contributes to induction of enhanced SLE memory T cell survival, and its pathway was frequently activated in SLE patient PBMC and $T$ cells, more markedly in active disease phases ${ }^{[26]}$. Not only that the magnitude of PI3K pathway activation in patients with SLE paralleled activated/memory T cell accumulation ${ }^{[26]}$. Therefore, PI3K pathway may involve in human SLE.

A heterozygous mutation, c.38 A>G (p.G13C) in NRAS gene, was identified in patient1-4. Neither parent harbored a mutation in the NRAS gene, suggesting that the patient harbored a de novo germline or somatic mutation. Using DNA extracted from somatic cells (nails and buccal mucosa), NRAS exon 1 was amplified by PCR. Then the products were cloned. Mutated alleles were observed less frequently in the buccal mucosa and nails ( 42.8 , and $8.8 \%$, respectively) than in the blood $(52.0 \%)$ in patient 1 . Similar results were found in other three patients. Consequently, these patients harbored a somatic NRAS mutation. Obvious

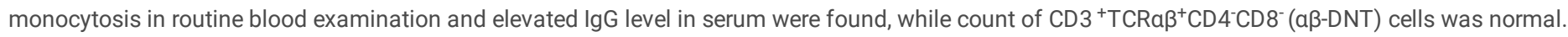
These four patients fulfilled RALD diagnosis based on lymphoproliferation, autoimmune cytopenia, and without a defect in FAS-dependent apoptosis or an increase in peripheral aß-DNT cells.

NRAS is a member of the p21 small GTPase family of proteins that also includes HRAS and KRAS. Germline RAS mutations are associated with specific developmental disorders, including Noonan (NS; OMIM 613224), Costello (OMIM 218040), and cardio-facio-cutaneous syndromes (OMIM 115150) [27, 28]. Somatic RAS mutations are seen in $30 \%$ of all human cancers. Previous study has been confirmed that the G13D NRAS mutation in germline cell causes BIM downregulation and defective intrinsic mitochondrial apoptosis prominently in lymphocytes, leading to RALD and hematopoietic malignancies ${ }^{[15]}$. However, another study revealed somatic mosaicism, again for the G13D NRAS mutation, causes BIM downregulation in activated T cells from children's patient, leading to RALD and juvenile myelomonocytic leukemia (JMML) ${ }^{[9]}$. Western blot analysis in our study showed that BIM levels in PBMCs from these four patients were markedly reduced, whereas those in control was normal. However, our patients all presented with SLE. Thus, SLE may be a novel phenotype of patient with somatic NRAS mutation. Interestingly, both germinal and somatic mutations in NRAS gene both might be involved in the pathogenesis of autoimmune diseases.

RASopathies are autosomal dominant neurodevelopmental syndromes resulting from germline mutations in genes that participate in the rat sarcoma/mitogen-activated protein kinases (RAS/ MAPK) pathway, an important signal transduction pathway through which extracellular ligands stimulate cell proliferation, differentiation, survival, and metabolism ${ }^{[29,30]}$. The association between RASopathies and autoimmunity has been highlighted by the presence of autoimmune antibodies in $52 \%$ of 42 patients with RASopathies, including $39 \%$ of 37 NS patients [31]. Of these, six patients fulfilled the clinical criteria for autoimmune diseases, including SLE ${ }^{[31]}$. The prevalence of NS and SLE is approximately 1 per 2000 births and 3.3-24 per 100000 children, respectively ${ }^{[30,32]}$. The relationship of these two rare diseases and the high overall percentage of patients with NS who have autoimmune features suggest that they might be related and that RASopathies must be added to this growing list of monogenic SLE, including NRAS gene mutation.

In the typical form of SLE, SLE is considered a disease of women of reproductive age, although males or females of any age can be affected. It is very rare in less than 5 years. The typical age at diagnosis is between 15 and 45 years. The female to male ratio varies among cohorts but is generally estimated at about 9:1 and 4:1 in adult and child onset disease, respectively ${ }^{[32,33]}$. The more common early manifestations are arthritis, photosensitive rashes, glomerulonephritis, and cytopenias. Of these patients with mutations in our study, the most common affected systems or features were renal (6/6 patients) and hematological (6/6patients) involvement, and recurrent fever (6/6patients) while only one patient presented with skin involvement. Average age onset is 4 years. Thus, SLE differs from classic SLE presentation by a higher male-to-female ratio of 1:1, a lower rate of skin involvement (1/6 patients), and the occurrence of a lymphoproliferative disorder in some patients. 
A few previous reports showed that patients with somatic NRAS or KRAS mutations could follow a more benign clinical course requiring minimal medications

$\left[{ }^{[9}{ }^{30}\right.$. However, MAS was observed in patient 1 at the beginning, and in patient 3 after disease flare, both characterized by fever, multilineage cytopenia, hyperferritinemia, hypertriglyceridemia and hypofibrinogenemia. Our patients all was treated with oral prednisolone and suppressive agent, and methylprednisolone pulse therapy was given to patient $1,4,5$ at the beginning, because of severe conditions. Clinical features were improved rapidly after treatment. However, the disease was flare again when oral doses of prednisolone was tapered to $1.25 \mathrm{mg}$ per day to $5 \mathrm{mg}$ per day in three patients $(1,3,4)$. Therefore, we think SLE complicated with lymphoproliferative disorder, caused by associated gene mutations, is not benign disease. In addition, it is not yet clear whether patients with somatic NRAS mutations progress to full blown disease, and maintain a stable clinical course. These patients need be monitored carefully.

No mutations in genes, associated with monogenic SLE and primary immunodeficiencies, were detected in patient 5 . She presented with persistently cervical lymphadenopathy, proteinuria and hematuria, and purpura in in lower limbs, no recurrent fever and hematological involvement, which are different with those with mutations in this study.

\section{Conclusion}

SLE may be a novel phenotype of germline mutation in PI3CKD gene and somatic mutation in NRAS gene. These genes, NRAS, TNFAIP3 and PIK3CD, should be considered as candidates for children SLE with lymphoproliferation. If patients with SLE and lymphoproliferation presented with renal and hematological involvement, and recurrent fever, they need gene testing, especially in male patient.

\section{Abbreviations}

ACR:American College of Rheumatology; ALT:Alanine Aminotransferase; ALPS:Autoimmune lymphoproliferative syndrome; ANA:Antinuclear antibody; BIM:Mediator of Cell Death; CTX:cyclophosphamide; EDTA:ethylenediaminetetraacetic acid; EULAR:European League Against Rheumatism; GC:glucocorticoid; GOF:Gain-of-Function; GOT:Glutamic-oxalacetic Transaminase; HA20:haploinsufficiency of A20; HCQ:hydroxychloroquine; IL2RA:Interleukin-2 receptor a; LDH:lactate dehydrogenase; MAS:macrophage activation syndrome; MMF:mycophenolate mofetil; OMIM:Online Mendelian Inheritance in Man; PBMCs:peripheral blood mononuclear cells; PBS:phosphate-buffered saline; RALD:RAS-associated Autoimmune Leukoproliferative disease; SDS-PAGE:sodium dodecyl sulfate polyacrylamide gel electrophoresis; SLE:Systemic lupus erythematosus; STAT3:Signal transducer and activator of transcription 3; WES:whole exome sequencing; $a \beta-D N T: C D 3+T C R a \beta+C D 4-C D 8-$;

\section{Declarations}

\section{Acknowledgements}

Many thanks to the patients and their parents.

\section{Funding}

This work was not supported by any project.

\section{Availability of data and materials}

The datasets are not publicly available but are available from the first author on reasonable request.

\section{Ethics approval and consent to participate}

Ethics board approval and consent was obtained for this work from the Ethics Committee at the Children's Hospital of Fudan University, Shanghai, China (ekyy-2011-48).

\section{Authors' contributions}

LS, G-m L participated in research design. Y-f L, G-w Z, G-mL, TZ, LS and H-mL participated in the writing of the paper. B-b W, G-mL, TZ, LS, S Y and H-mL participated in the performance of the research. HX, G-mL, WY and LS participated in data analysis. All authors read and approved the final manuscript.

\section{Consent for publication}

Not applicable.

\section{Competing interests}

The authors declare that they have no competing interests.

\section{Author details}

1Children's Hospital of Fudan University, 399 Wanyuanlu, Shanghai 201102,

China. 2Institutes of Biomedical Sciences of Fudan University, 220 Handanlu, 


\section{References}

1. Schmidt RE, Grimbacher B, Witte T. Autoimmunity and primary immunodeficiency: two sides of the same coin? Nat Rev Rheumatol, 2017, 14(1):7-18.

2. Bride K, Teachey D. Autoimmune lymphoproliferative syndrome: more than a FAScinating disease. F1000Res, 2017, 6:1928.

3. Takagi M, Shinoda K, Piao J, Mitsuiki N, Takagi M, Matsuda K, et al. Autoimmune lymphoproliferative syndrome-like disease with somatic KRAS mutation. Blood, 2011 117(10):2887-90.

4. Fabre A, Marchal S, Barlogis V, Mari B, Barbry P, Rohrlich PS, et al. Clinical Aspects of STAT3 Gain-of-Function Germline Mutations: A Systematic Review. J Allergy Clin Immunol Pract, 2019, 7(6):1958-1969.

5. Goudy K, Aydin D, Barzaghi F, Gambineri E, Vignoli M, Ciullini Mannurita S, et al . Human IL2RA null mutation mediates immunodeficiency with lymphoproliferation and autoimmunity. Clin Immunol, 2013, 146(3):248-61.

6. Tsokos GC. Systemic lupus erythematosus. N Engl J Med, 2011, 365(22):2110-21.

7. Batu ED, Koşukcu C, Taşkıran E, Sahin S, Akman S, Sözeri B, et al. Whole Exome Sequencing in Early-onset Systemic Lupus Erythematosus. J Rheumatol. 2018, 45(12):1671-1679.

8. Niemela JE, Lu L, Fleisher TA, Davis J, Caminha I, Natter M, et al. Somatic KRAS mutations associated with a human nonmalignant syndrome of autoimmunity and abnormal leukocyte homeostasis. Blood, 2011, 117(10):2883-6.

9. Shiota M, Yang X, Kubokawa M, Morishima T, Tanaka K, Mikami M, et al. Somatic mosaicism for a NRAS mutation associates with disparate clinical features in RAS-associated leukoproliferative disease: a report of two cases. J Clin Immunol, 2015, 35(5):454-8.

10. Aringer M, Costenbader K, Daikh D, Brinks R, Mosca M, Ramsey-Goldman R, et al. 2019 European League Against Rheumatism/American College of Rheumatology Classification Criteria for Systemic Lupus Erythematosus. Arthritis Rheumatol, 2019, 71(9):1400-1412.

11. Li GM, Cao Q, Shen Q, Sun L, Zhai YH, Liu HM, et al. Gene mutation analysis in 12 Chinese children with congenital nephrotic syndrome. BMC Nephrol, 2018, 19(1):382.

12. Price S, Shaw PA, Seitz A, Joshi G, Davis J, Niemela JE, et al. Natural history of autoimmune lymphoproliferative syndrome associated with FAS gene mutations. Blood, 2014, 123(13):1989-99.

13. Martínez-Feito A, Melero J, Mora-Díaz S, Rodríguez-Vigil C, Elduayen R, González-Granado LI, Pérez-Méndez D, et al. Autoimmune lymphoproliferative syndrome due to somatic FAS mutation (ALPS-SFAS) combined with a germline caspase-10 (CASP10) variation. Immunobiology, 2016, 221(1):40-7.

14. Tripodi SI, Mazza C, Moratto D, Ramenghi U, Caorsi R, Gattorno M, et al. Atypical presentation of autoimmune lymphoproliferative syndrome due to CASP10 mutation. Immunol Lett, 2016,177:22-4.

15. Oliveira JB, Bidère N, Niemela JE, Zheng L, Sakai K, Nix CP, et al. NRAS mutation causes a human autoimmune lymphoproliferative syndrome.Proc Natl Acad Sci U S A, 2007, 104(21):8953-8.

16. Flanagan SE, Haapaniemi E, Russell MA, Caswell R, Allen HL, De Franco E, et al. Activating germline mutations in STAT3 cause early-onset multi-organ autoimmune disease. Nat Genet, 2014,46(8):812-814.

17. Nabhani S, Schipp C, Miskin H, Levin C, Postovsky S, Dujovny T, et al. STAT3 gain-of-function mutations associated with autoimmune lymphoproliferative syndrome like disease deregulate lymphocyte apoptosis and can be targeted by BH3 mimetic compounds. Clin Immunol, 2017,181:32-42.

18. Li GM, Liu HM, Guan WZ, Xu H, Wu BB, Sun L. Expanding the spectrum of A20 haploinsufficiency in two Chinese families: cases report. BMC Med Genet, 2019, 20(1):124.

19. Zhou Q, Wang H, Schwartz DM, Stoffels M, Park YH, Zhang Y,et al. Loss-of-function mutations in TNFAIP3 leading to A20 haploinsufficiency cause an early-onset autoinflammatory disease. Nat Genet, 2016, 48(1):67-73.

20. Duncan CJA, Dinnigan E, Theobald R, Grainger A, Skelton AJ, Hussain R, et al. Early-onset autoimmune disease due to a heterozygous loss-of-function mutation in TNFAIP3 (A20). Ann Rheum Dis, 2018,77(5):783-786.

21. Takagi M, Hoshino A, Yoshida K, Ueno H, Imai K, Piao J, et al. Genetic heterogeneity of uncharacterized childhood autoimmune diseases with lymphoproliferation. Pediatr Blood Cancer, 2018, 65(2).

22. Takagi M, Ogata S, Ueno H, Yoshida K, Yeh T, Hoshino A, et al. Haploinsufficiency of TNFAIP3 (A20) by germline mutation is involved in autoimmune lymphoproliferative syndrome. J Allergy Clin Immunol, 2017, 139(6):1914-1922.

23. Li GM, Liu HM, Guan WZ, Xu H, Wu BB, Feng JY, et al. A mutation in PIK3CD gene causing pediatric systemic lupus erythematosus: A case report. Medicine (Baltimore), 2019, 98(18):e15329.

24. Angulo I, Vadas O, Garçon F, Banham-Hall E, Plagnol V, Leahy TR,et al. Phosphoinositide 3-kinase $\delta$ gene mutation predisposes to respiratory infection and airway damage. Science, 2013, 342(6160):866-71.

25. Lucas CL, Chandra A, Nejentsev S, Condliffe AM, Okkenhaug K. PI3Kס and primary immunodeficiencies. Nat Rev Immunol, 2016,16(11):702-714.

26. Suárez-Fueyo A, Barber DF, Martínez-Ara J, Zea-Mendoza AC, Carrera AC. Enhanced phosphoinositide 3-kinase $\delta$ activity is a frequent event in systemic lupus erythematosus that confers resistance to activation-induced T cell death. J Immunol, 2011, 187(5):2376-85.

27. Altmüller F, Lissewski C, Bertola D, Flex E, Stark Z, Spranger S, et al. Genotype and phenotype spectrum of NRAS germline variants. Eur J Hum Genet. 2017, 25(7):823-831.

28. Park PG, Park E, Hyun HS, Kang HG, Ha IS, Cho TJ, et al. Cutaneous Skeletal Hypophosphatemia Syndrome in Association with a Mosaic HRAS Mutation. Ann Clin Lab Sci, 2018, 48(5):665-669. 
29. Rauen KA. The RASopathies. Annu Rev Genomics Hum Genet, 2013,14:355-69.

30. Bader-Meunier B, Cavé H, Jeremiah N, Magerus A, Lanzarotti N, Rieux-Laucat F, et al . Are RASopathies new monogenic predisposing conditions to the development of systemic lupus erythematosus? Case report and systematic review of the literature. Semin Arthritis Rheum, 2013, 43(2):217-9.

31. Quaio CR, Carvalho JF, da Silva CA, Bueno C, Brasil AS, Pereira AC, et al. Autoimmune disease and multiple autoantibodies in 42 patients with RASopathies. Am J Med Genet A, 2012, 158A(5):1077-82.

32. Harry O, Yasin S, Brunner H. Childhood-Onset Systemic Lupus Erythematosus: A Review and Update. J Pediatr, 2018, 196:22-30.

33. Mina R, Brunner HI. Update on differences between childhood-onset and adult-onset systemic lupus erythematosus. Arthritis Res Ther, $2013,15(4): 218$.

\section{Figures}

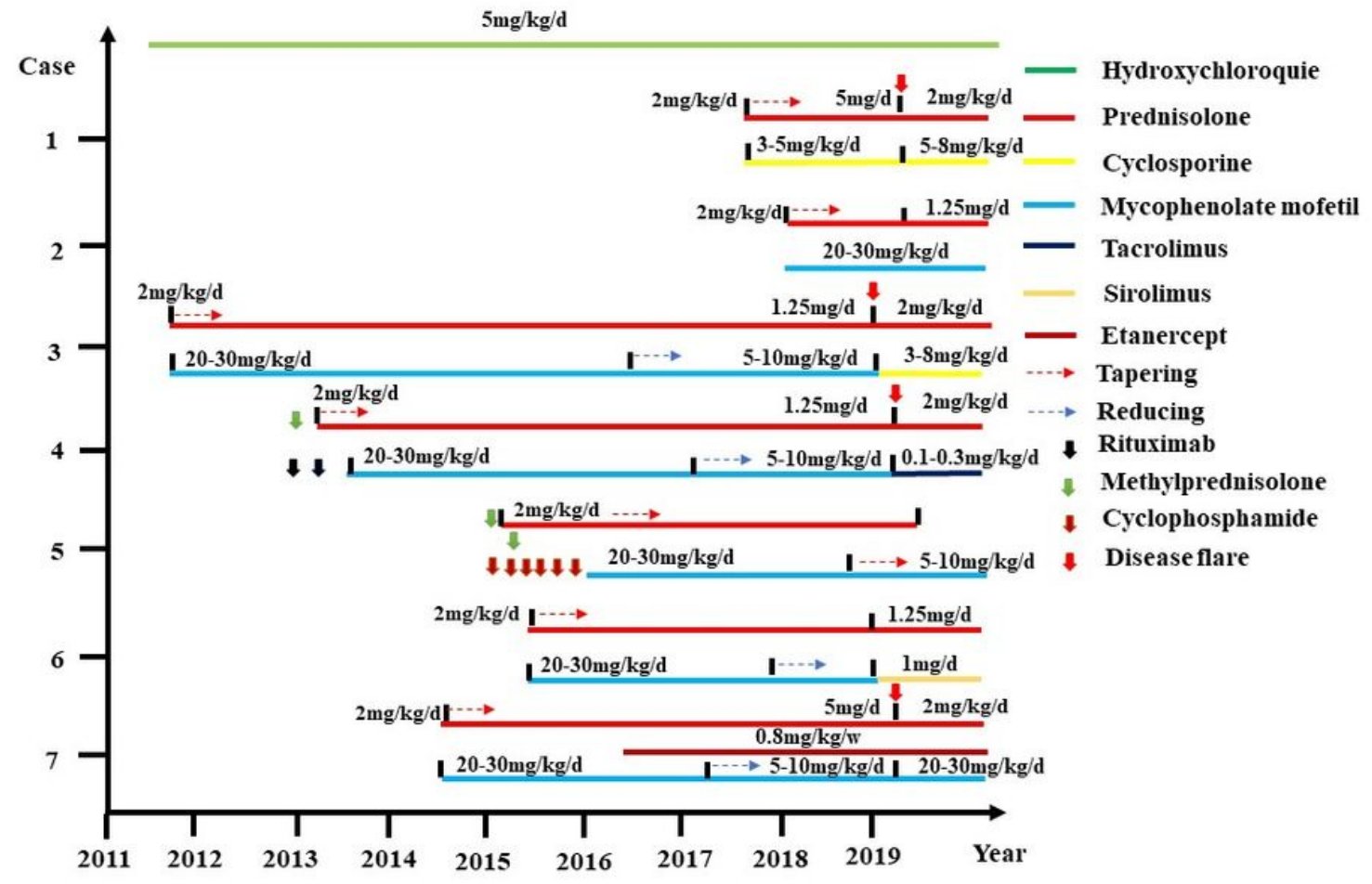

Figure 1

Therapies for all patients. 


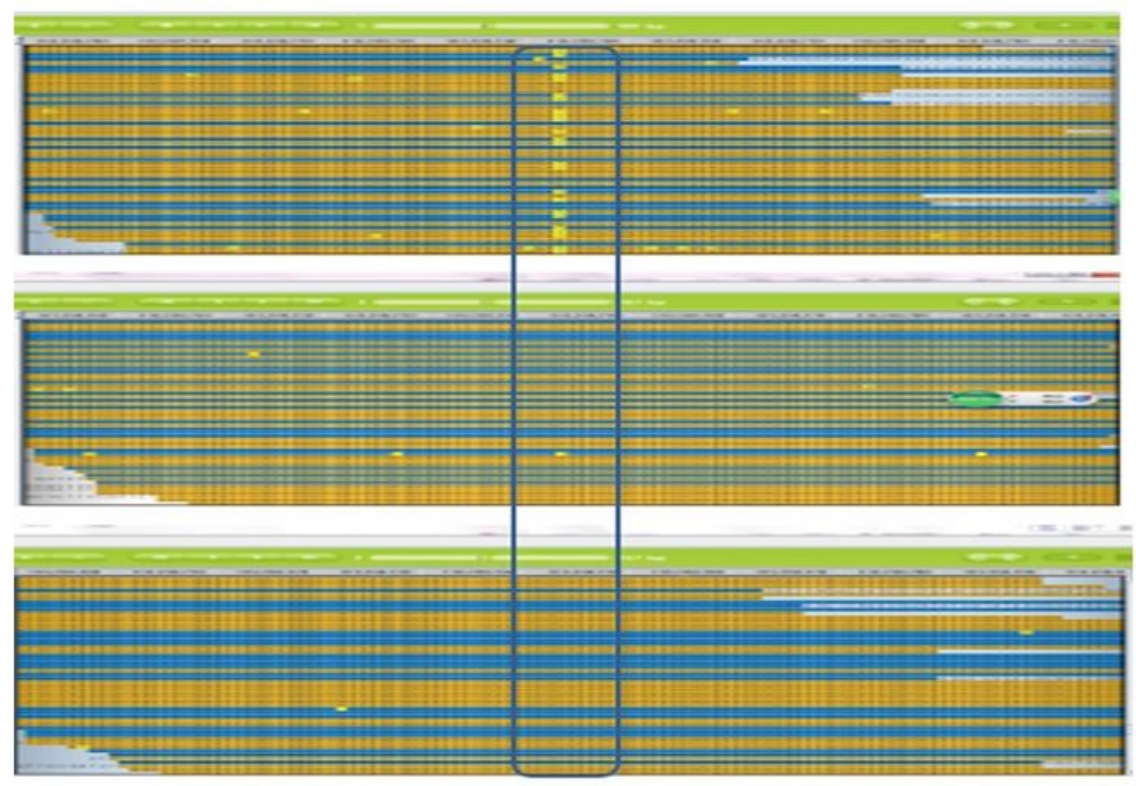

NRAS: NM_002524, Ex1, c.38G>A, p.G13D (1352/2600, 52\%) in P1

\section{Figure 2}

A heterozygous mutation in the NRAS gene (c.38G>A, p.G13D, 52\%) was detected in monocytes collected from peripheral blood of patient 1. No mutation was identified in his parents.

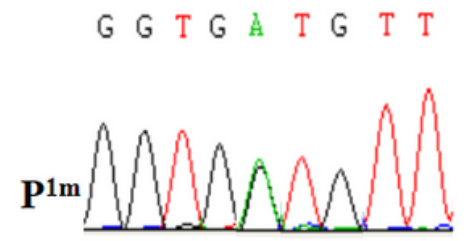

A: $52.0 \%$
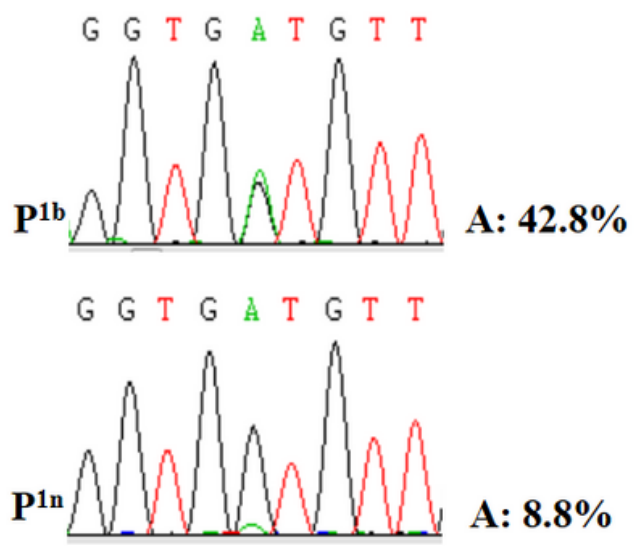

A: $8.8 \%$

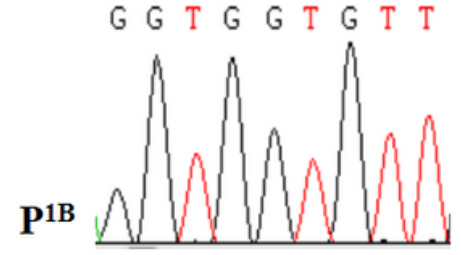

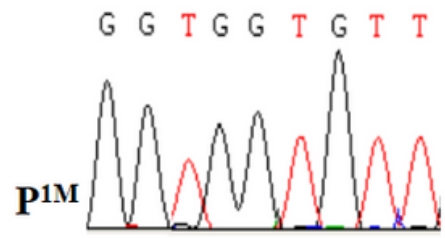

G G T G G T G T T

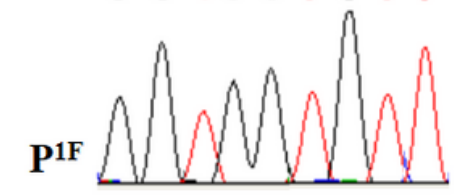

A: $0.0 \%$

\begin{tabular}{llllll} 
& Sample & \multicolumn{4}{c}{ Frequency (\%) } \\
\cline { 3 - 6 } A: 0.0\% & & Patient 1 & Patient 2 & Patient 3 & Patient 4 \\
\cline { 2 - 6 } & Peripheral blood & 52.0 & 43.8 & 48.6 & 50.0 \\
& Buccal mucosa & 42.8 & 23.1 & 26.3 & 22.4 \\
& Nail & 8.8 & 12.0 & 10.2 & 11.7 \\
\hline
\end{tabular}

b

A: $0.0 \%$ 
The mutation c.38G>A confirmed by Sanger sequencing. a) P1m: Monocyte of patient 1; P1b: Buccal mucosa of patient 1; P1n: Nail of patient 1; P1F: Father of patient 1; P1M: Mother of patient 1; P1B: Brother of patient 1, b) Frequency of the mutated allele (A) varied in different tissues from patients.

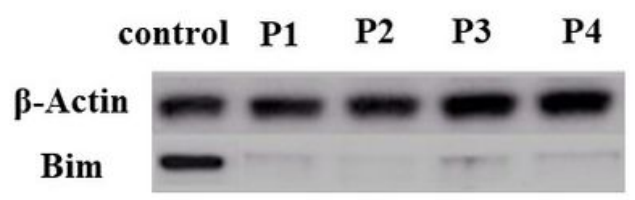

Figure 4

Western Blot BIM and $\beta$-actin are shown for patients 